\title{
The research and implementation of desulfurization monitoring system
}

\author{
Wendong $\mathrm{Ji}^{1, \mathrm{a}}$, Lijian Zhang ${ }^{1, \mathrm{~b}}$, Yuzhen Cao ${ }^{2, \mathrm{c}}$, Tingting Wang ${ }^{3, \mathrm{~d}}$ \\ ${ }^{1}$ College of Electrical Engineering, Binzhou Polytechnic, Shandong, 256600, China \\ ${ }^{2}$ State grid binzhou power supply company \\ ${ }^{3}$ Bohai Piston Co.,Ltd, Binzhou, Shandong, 256600,China \\ axianruibrother@163.com, b,c41350992@qq.com, ${ }^{\text {c} 1653226361 @ q q . c o m ~}$
}

\begin{abstract}
With the development of economy, are the main sources of air pollution of sulfur dioxide, seriously affecting the quality of life of the people. Improve the desulphurization is an important part of today's enterprise production. The desulfurization system is complex, high to the requirement of control system. After sufficient demonstration, the control system and control scheme is optimized, this set of PLC control flue gas desulfurization system is designed and developed. System running stability is high, greatly reduces the maintenance workload, flue desulphurization rate increased by $21 \%$ than the original system.
\end{abstract}

Keywords: Sulfur, Dioxide, Desulfurization, PLC, Control.

\section{Introduction}

Coal is the main fuel, which causes air pollutants to be mainly smoke and sulfur dioxide, and the acid rain is harmful to the area, which seriously affects the health of plants and human beings. Therefore, effective control of sulfur dioxide in flue gas is essential to improve the environment. The control technology of SO2 is divided into three types: pre-combustion desulfurization, desulphurization and post-combustion desulfurization after combustion in coal combustion.

The equipment is based on huichuan PLC, which is the upper computer based on Beijing kunlun tongtai MCGS. The system adopts the PID control, cascade control and switch volume control, and has two operation modes: manual and automatic. The system is easy to operate, stable and easy to maintain.

\section{System introduction}

\section{Technological process}

The desulfurization system is composed of chimney, desulfurization absorption tower, circulating pool, lime tank, lye tank, pressure filter machine drying field, etc. The various components work together to ensure the stable operation of the whole system. The entire process is shown in figure 1.

The desulphurization of the desulfurization absorber and the lime in the circulating tank were chemically reacted, and the sodium alkaloid successively completed the first regeneration and the second regeneration process. Adjust the amount of lime slurry and alkali liquor according to the $\mathrm{PH}$ value.

\section{Requirements of control loop}

$\mathrm{PH}$ automatic regulating circuit (range $0-14 \mathrm{ph}$ )

Start off the valve SV013DO-KG with PH value and turn off the valve when the $\mathrm{PH}$ value $>6$. Open the valve at 4.

SO 2 automatic regulating circuit (range 0-2000mg /NM3)

(1) starting order: A--B--C pump; Single loop automatic adjustment (single pump running a given value $0-2000 \mathrm{mg}$ adjustable) 
At the given value of $>$, the A circulating water pump is activated, which is automatically adjusted according to the SO.

(2) cascade adjustment

When the A pump runs 1200 ", SO the concentration of SO is higher than 200MG, and the pump operation forms A cascade regulating loop, and the B pump is automatically adjusted with the concentration of SO, and the A pump is running at A steady speed.

(3) manual intervention

$\mathrm{A} / \mathrm{B}$ pump starts operation, SO the concentration is higher than the design concentration.

Cleaning pump number SV007DO-KG.

It has the function of manual and automatic operation. The panel sets the fixed value and can modify the running time, according to the process or operating experience value to put in the running time and stop interval time. 30 minutes apart, run 45-60. The flushing pressure is controlled between 140 and $280 \mathrm{Kpa}$.

Automatic interlocking state (the soft contact point of PLC control loop of flue gas lift is delayed 5 seconds)

The screen sets the interlock input resection button.

(1) when the temperature of the absorber inlet temperature T1, T2 any $>100^{\circ}$ and the entrance of $21 \%$ oxygen, close, 2 \# 1 furnace flue damper SV018DO - KG SV019DO - KG, open flue gas lift SV014DO - K, SV016DO - K, start the circulation pump run A SV001DO - KG force $600 "$.

(2) below $100^{\circ}$ startup sequence when the first open A circulating water pumps running 60 , to open flue damper SV018DO - KG SV019DO - KG.

(3) the circulating pump does not open the flue to adjust the damper.

Adjust the automatic drop button of the damper.

2 sets of 2 \# furnace flue respectively installed smoke electric control valve, adjustable within the range of $90^{\circ}$. Open conditions: flue inlet temperature $<100^{\circ}$, circulating water pump is open, the entry for less than $21 \%$ oxygen.

Historical records

The record points are: circulating pump start and stop instructions, the inlet and outlet temperature of the flue, SO the concentration, and the flue regulating the air door opening and closing instruction information, the $\mathrm{PH}$ value.

\section{Network type and control mode.}

According to the principle of "control decentralization and centralized management", distributed network structure is adopted. The desulfurization control system consists of DCS monitoring station, PLC control process station, field instrument station and electrical control cabinet. PLC control process station is composed of PLC and touch screen, which facilitates the operation of process personnel, and realizes the signal interaction with DCS monitoring station through field bus. The computer of DCS monitoring station is connected to the enterprise management computer through Ethernet, realizing the automation and efficient operation of the whole system.

This system realizes two operation modes by switching switch, namely manual mode and automatic mode. All field signals, including pumps, valves and $\mathrm{PH}$ values, were collected through the PLC extension module and finally recorded in the DCS monitoring room.

\section{System design}

\section{System hardware design.}

The whole control system selects the H2U series PLC produced by the domestic huichuan company, the model H2U-2416MR,

PLC system includes a power supply module, a CPU units, digital quantity input/output module, analog input and output module, temperature module, respectively, 1 piece of enn, 2 pieces of $\mathrm{H} 2 \mathrm{U}$ H2U - 0800-4 AD, 1 piece of $\mathrm{H} 2 \mathrm{U}$ - 4 pt, 1 piece of $\mathrm{H} 2 \mathrm{U}-4 \mathrm{am}$. 


\section{Software design}

Inovance company use special programming software Autoshop V2.07 for controller, write support function block, ladder diagram and instruction list program mode, the programming software developed with mitsubishi PLC software can mix. The desulphurization monitoring PLC control program includes two parts: main program and interrupt program. The main program to complete parameter initialization, throttle, cleaning pump, such as control, the interrupt service routine PID control, complete the SO2 concentration containing SO2 data acquisition, data scale transform, manual switch and PID control algorithm, PID control algorithm is shown in the following program.

$\begin{array}{lc}\text { // collect the values of SO2.LD } \\ \text { FROM } & \text { K0 K7 D50 K1 } \\ \text { LD } & \text { M8000 } \\ \text { DESUB } & \text { K200 K0 D20 } \\ \text { DESUB } & \text { K1000 K0 D22 } \\ \text { DEDIV } & \text { D20 D22 D24 } \\ \text { DEMUL } & \text { D24 D50 D48 } \\ \text { INT } & \text { D48 D62 }\end{array}$

//PID control d62 value d62 measurement d300 parameter setting (25), output value d64, M39 B pump operation, A pump fixed speed operation to remove PID control.LD M8000

$\begin{array}{lc}\text { ANI } & \text { M39 } \\ \text { PID } & \text { D226 D62 D200 D64 } \\ / / 11 / 5000 & \\ \text { Physical quantity transform 4DA mod } & \text { M8000 } \\ \text { LD } & \text { M39 } \\ \text { ANI } & \text { K1000 K0 D30 } \\ \text { DESUB } & \text { K32767 K0 D32 } \\ \text { DESUB } & \text { D30 D32 D34 } \\ \text { DEDIV } & \text { D34 D64 D38 } \\ \text { DEMUL } & \text { D38 D66 }\end{array}$

//The 4\#-4DA module sets the channel 1 to the A circulating pump.

\begin{tabular}{ll} 
LD & M8000 \\
ANI & M39 \\
TOP & K4 K0 H1111 K1 \\
TO & K4 K1 D66 K1 \\
LD & M8000 \\
AND & M39 \\
PID & D226 D62 D300 D68 \\
LD & M8000 \\
AND & M39 \\
DESUB & \multicolumn{1}{c}{ K1000 K0 D40 } \\
DESUB & K32767 K0 D42 \\
DEDIV & \multicolumn{1}{c}{ D40 D42 D44 } \\
DEMUL & \multicolumn{1}{c}{ D44 D68 D28 } \\
INT & D28 D70 \\
LD & M8000 \\
AND & M39 \\
TOP & K4 K0 H1111 K1 \\
TO & K4 K2 D70 K1
\end{tabular}




\section{Monitoring configuration}

The MCGS software consists of five parts: main control window, device window, user window, real-time database and operation strategy. The configuration of the upper computer monitor software includes the window configuration, I/O connection, database creation, animation configuration and script writing. The window configuration completes the window properties, the layout of the screen and the call. I/O connection completes monitoring software and PLC serial communication connection to realize data interaction. Real-time database completion variable definition, is the data exchange center of each part. The functions of other parts are not detailed.

Some running policy procedures: $\mathrm{W}_{-} 1=1 /\left(\mathrm{SM}_{-} 1^{\wedge} 2\right)$

Merge W_2 $=1 /($ merge SM_2^ 2$)$

Merge W_3 $=1 /\left(\right.$ merge $\mathrm{SM}_{-} 3^{\wedge}$ 2)

Merge W_4 $=1 /\left(\right.$ merge $\left.\mathrm{SM}_{-}^{-} 4^{\wedge} 2\right)$

Merge W_5 = 1/(merge SM_5^2)

Merge W_6 $=1 /($ merge SM_6^ 2$)$

With the mean $\mathrm{M}=$ (merger $\mathrm{W} \_1 * \mathrm{M} \_1+\mathrm{W} \_2 * \mathrm{M} \_2+\operatorname{merger} \mathrm{W} \_3 * \mathrm{M}$ 3 $+\mathrm{W} \_4 * \mathrm{M} \_4+\operatorname{merger} \mathrm{W} \_5 * \mathrm{M} \_5+\mathrm{W} \_6 *$ M_6)/(merger W_1 + W_2 + the combining $\bar{W} \_3+\overline{+}$ W_5 + the combining $\left.\mathrm{W} \_6 \overline{\mathrm{W}} \_4\right)$

Horizontal $\overline{\mathrm{SM}}=$ ! SQR $\left(1 /\left(\right.\right.$ merge $\mathrm{W} \_1+\overline{\mathrm{W}} \_2+$ merge $\mathrm{W} \_3+$ merge $\mathrm{W} \_4+$ merge W_5+ merge W_6 $\left.)\right)$

So $\mathrm{k}$ is equal to 6 'and the 3 dose is always equal to 6 .

$\mathrm{F}=\mathrm{m} *(\mathrm{~m}-1) *(\mathrm{k}-1)^{\prime}, 162$

If $\mathrm{m}=2$ then $2 * 1 * 5$

$\mathrm{T}=2.2281$

endif

If $\mathrm{m}=3$ then $' 3 * 2 * 5$

$\mathrm{T}=2.0423$

endif

If $\mathrm{m}>=4$ then $4 * 3 * 5$

$\mathrm{T}=2.0423$

endif

FL upper limit of combined $\mathrm{M}$ mean = combined $\mathrm{M}$ mean + merged $\mathrm{t} *$ combined with horizontal SM.

FL lower limit of combined $\mathrm{M}$ means $=$ combined $\mathrm{M}$ mean - merged $t^{*}$ combined with horizontal SM.

The mean merger $\mathrm{PT}=10^{\wedge} \mathrm{M}$

Merger PT FL limit $=10^{\wedge} \mathrm{M}$ average FL limit

Merger PT FL lower limit $=10^{\wedge} \mathrm{M}$ average FL limit

The FL trusted limit for the combination of PT =(the FL upper limit of the combined PT - combined PT)/ merged PT*100.

Combine PT with FL trusted limit $b=$ ! STR (combined PT's FL confidence limit)+"\%"

Its party $=\left(\right.$ merge $\mathrm{W} \_1 * \mathrm{M} \_1 \wedge 2+\mathrm{W} \_2 * \mathrm{M} \_2^{\wedge} 2+$ the combining $\mathrm{W} \_3 * \mathrm{M} \_3{ }^{\wedge} 2+\operatorname{merger} \mathrm{W} \_4 * \mathrm{M} \_4^{\wedge} 2+$ merger $\mathrm{W} \_5$ $\left.* \mathrm{M} \_5^{\wedge} 2+\operatorname{merger} \mathrm{W} \_6{ }^{*} \mathrm{M} \_6^{\wedge} 2\right)-\left(\operatorname{merger} \mathrm{W} \_1 * \mathrm{M} \_1+\mathrm{W} \_2 * \mathrm{M} \_2+\operatorname{merger} \mathrm{W} \_3 * \mathrm{M} \_3+\mathrm{W} \_4 * \mathrm{M} \_\overline{4}+\operatorname{merger} \mathrm{W} \_5 * \overline{\mathrm{M}} \_5\right.$ $\left.+\mathrm{W} \_6 * \mathrm{M} \_6\right)^{\wedge} 2 /\left(\operatorname{merger} \mathrm{W} \_1+\mathrm{W} \_2+\right.$ the combining $\mathrm{W} \_3 \overline{+}+\mathrm{W} \_\overline{5}+$ the combining $\left.\mathrm{W} \_\overline{6} \mathrm{~W} \_4\right)$

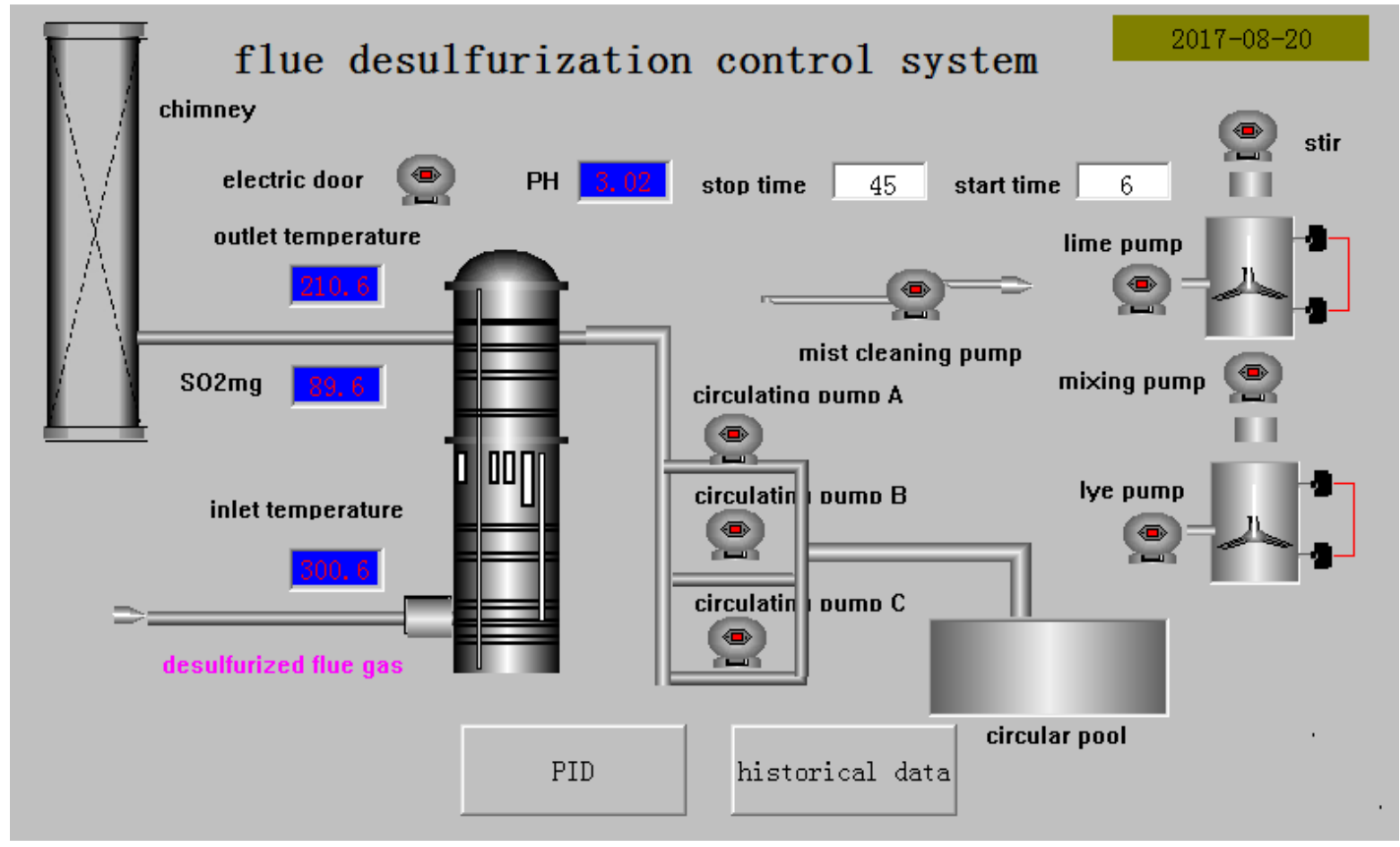

Fig.1 monitoring interface 


\section{Operation effect}

(1) process flow screen shows the process flow of desulfurization equipment, and provides a vivid image process interface for the process personnel to monitor the operation status and control of production equipment.

(2) real-time curve and historical curve of process data, the past and present of the process data can be viewed through the curve, which really brings great convenience to the management of production process.

(3) powerful alarm function is set up, and real-time processing is powerful, covering all input and output points of desulfurization equipment. Since put into production, the technology personnel reflect this equipment recorded more than 2000300 analog digital alarm and alarm, greatly shortens the time of technological personnel troubleshooting conveniently in a short period of time to resume production.

\section{Conclusion}

Through the half a year's operation, proved that the newly developed equipment operation is stable, low failure rate, in the event of failure, troubleshooting time is short, shorten the recovery time of equipment, improved the operation efficiency of enterprises.

\section{Acknowledgement}

The research was financially supported by Colleges and universities in shandong province department of education scientific research and development projects.

Project name:research and implementation of automatic control system for flue gas desulfurizationwith item number: J17KB132

The research is supported by the research project of binzhou vocational college.

Project name: the research and application of integrated monitoring system of intelligent distribution room based on cloud platform, project no. :2017YJKT15.

\section{Reference}

[1] Li Renchong. Forming a one-time exhaust airway Chinese die [P].: 201020183972.62010-5-17.

[2], Peng Yan, Wang Hai, Ding Yuanli, et al. Development and current situation of residential flue in China [J]. science and technology world, 2013 (21): 77.

[3], Xie Youbao, Xiong Xiao Ming, Yuan Gang, et al. Study on automatic production technology of integral shaping kitchen and sanitary exhaust duct [J]. concrete and cement products, 2012 (11): $39-42$.

[4] Xie Youbao, Yuan Gang, Xiong Xiaoming. Mould design for producing a new integral forming exhaust channel [J]. mechanical engineers, 2012 (8): 88-89.

[5] Du Wenjun. Equipment design of shock forming cement flue gas production line [D]. Wuhan: School of mechanical and electrical engineering, Wuhan University of Technology, 2014. 